\title{
Lateral sammenbunden tolkning -LCI-tolkning af geofysiske data
}

Af geofysiker Lars Hjortshøj Jacobsen og geofysiker Anders Edsen, Hedeselskabet Miljø og Energi A/S, og geofysiker Esben Auken, GeoFysikSamarbejdet

I denne artikel ønsker vi at diskutere brugen af laterale bånd i forbindelse med tolkningen af geoelektriske og elektromagnetiske data. Vi vil indføre læseren i princippet bag LCItolkning og redegøre for de bagvedliggende begreber. Vi vil også beskrive de fordele, der kan opnås ved brugen af laterale bånd i datatolkningen, men vil også understrege, hvilke fejl båndene kan introducere, hvis ikke de anvendes rigtigt.

Siden starten af 1990'erne er brugen af geoelektriske og elektromagnetiske metoder blevet meget udbredt i forbindelse med undersøgelsen af grundvandsressourcer og deres beskyttelse. Den øgede brug har samtidig givet anledning til, at der er blevet udviklet nye instrumenter, hvormed det inden for en økonomisk fornuftig ramme er muligt at opnå tæt opmålte datasæt langs profiler.

Traditionel tolkning

De målte data er traditionelt blevet tolket med én-dimensionale (1D) modeller, men i takt med den tættere datadækning og computernes voksende størrelser er ønsket om at kunne tolke data i en større dimension (2D og 3D) også vokset. Den én-dimensionale model består af homogene isotrope lag med uendelig, horisontal udstrækning. At denne simple model faktisk i mange tilfælde giver gode resultater skyldes to forhold. For det første "ser" en sedimentær lagfølge, inden for det forholdsvis lille jordvolumen, som de geofysiske metoder måler, meget "1D" ud. For det andet befinder metodernes opløsningsevne sig i meter til ti-meter skalaen, og derfor "ser" en lidt skrå laggrænse horisontalud.

Sideløbende med udviklingen af geofysiske måleudstyr er der blevet udviklet tolkningsprogrammer, således at det $i$ dag er muligt at tolke geoelektriske data ( $\mathrm{fx}$ MEP og PACES) med både 1D, 2D og 3D-modeller. Tolkningen af elektromagnetiske data (fx TEM og SkyTEM) foregår stadig udelukkende med 1D-modeller, idet beregningstiden forøges voldsomt med øget tolkningsdimension.

1D-LCI-princip, fordele og faldgrupper Siden slutningen af 1990'erne har em1 dinvkoden (tolkningsprogrammet Semdi og analyse programmet Emma er bygget ovenpå em1 dinv-koden, hvori alle beregninger fore- tages) været anvendt i forbindelse med tolkningen af TEM-data og senere tolkningen af MEP- og PACES-data. Med em 1 dinv er det muligt at bruge laterale bånd på modelparametrene (lagmodstand, lagtykkelse og/ eller lagdybde), hvorved information videreføres fra en model til en anden. Denne metodik kaldes 1D-LCI (Laterally Constrained Inversion), idet det er 1D-modeller, der bindes sammen med laterale bånd og derved resulterer i en pseudo 2D-model.

I figuren nedenfor ses en principskitse af 1D-LCI-metoden. Heri ses en serie af modeller, som alle har forskellig modstand ( $\rho)$, lagtykkelser (t) og lagdybder (d). Via båndene $(\mathrm{R})$ på parametrene overføres information mellem modellerne, hvilket resulterer i mere ensartede modeller.

Som grundlag for metodens teoretiske og praktiske anvendelighed har GeoFysikSamarbejdet udført flere store analysearbejder på profilorienterede geoelektriske og elektromagnetiske data samt sammentolkningen af disse (ref: $/ 1, / 2 / \mathrm{og} / 3 /$ ). Udfra dette arbejde kan man se, at med de rette båndstørrelser og typer er muligt, at 1D-LCI-tolke profilorienterede geoelektriske og elektromagnetiske data med succes. Dette afspejles $\mathrm{i}$, at der i de 1D-LCI-tolkede sektioner generelt opnås en forbedret opløsning af de geofysiske modeller, hvilket betyder, at der opnås bedre tilpasning mellem data og mo-

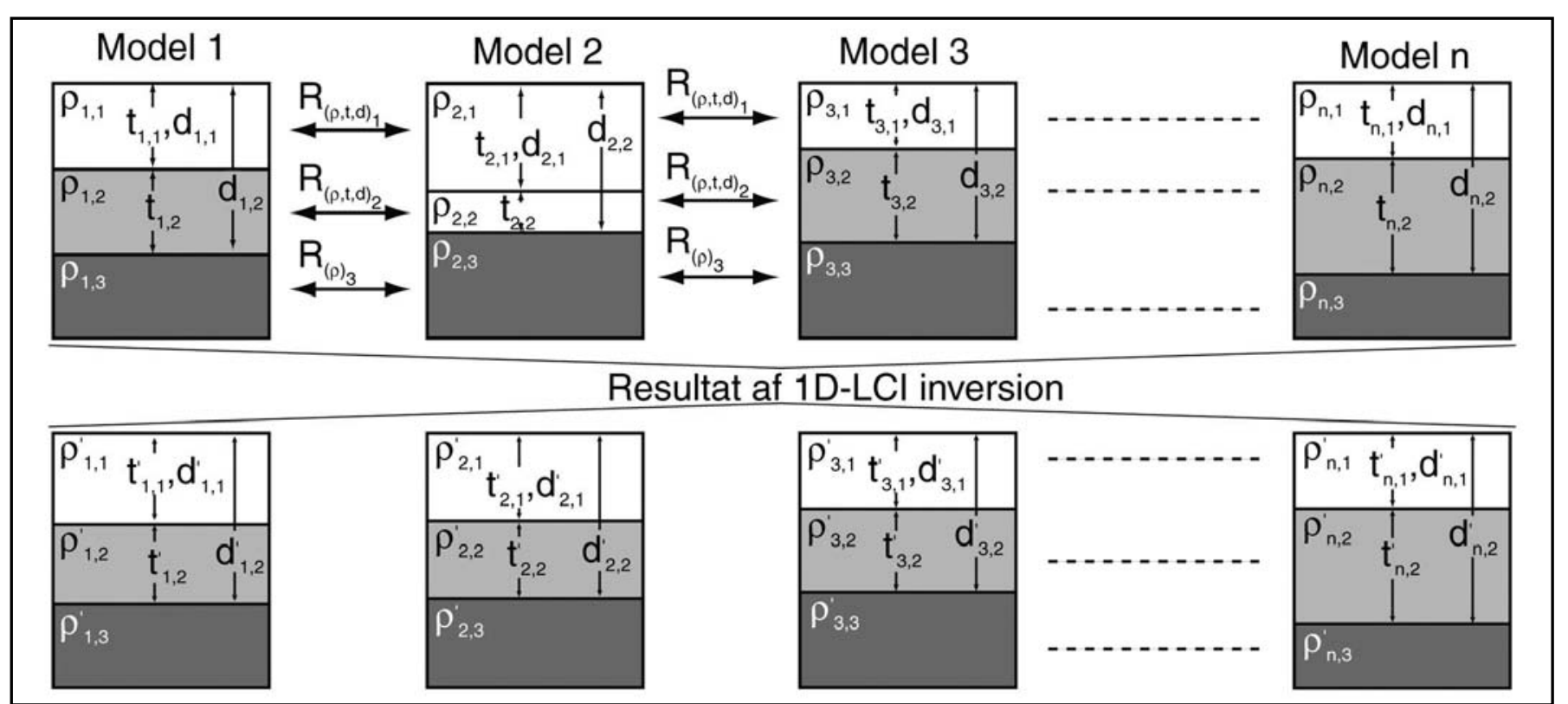

Principskitse af LCI-metoden. Øverst ses forskellige modeller, der via laterale bånd på modelparametrene bindes sammen. Dette resulterer i en udglatning, hvorved der opnås mere ens modeller. (Grafik: Lars H. Jacobsen) 
del, og at lagparametrene i højere grad bestemmes. Ydermere opnås en udglatning af modellerne, hvilket fører til, at uønskede tolkningseffekter fra en to- og tre-dimensional undergrund nedtones.

Forbedret oplosning af geologisk model Den opnåede forbedring i modelanalysen skyldes, at båndene bevirker, at alle sammenbundne modeller hjælper til med at opløse hinanden. Dette kan betragtes som en form for a priori-viden, hvor information om modelparametrene i hver enkelt model føres videre til de andre modeller. Denne binding af modelparametrene betyder inversionsmæssigt, at antallet af mulige modeller mindskes, hvorved der generelt opnås en forbedret opløsning af den geologiske model. Analysearbejdet viser imidlertid også, at det er altafgørende, at båndene har den rette styrke, idet båndene skal afspejle variationen i geologi mellem de sammenbundne modeller. Hvis båndene er for stramme, vil der blive tilført fejlagtig information i tolkningerne, idet båndene ikke vil tillade tilstrækkelig variation mellem de sammenbundne modeller. Hvis båndene derimod er



Illustration af to forskellige måder at anvende LCI-metoden på. Prikkerne reprosenterer modeller baseret på vekslende datatyper indikeret med farver. Stregerne viser, hvilke modeller der sammenbindes, mens langden af stregerne afspejler styrken af båndene. Jo langere streger desto svagere bånd og vice versa. (Grafik: Lars H. Jacobsen)

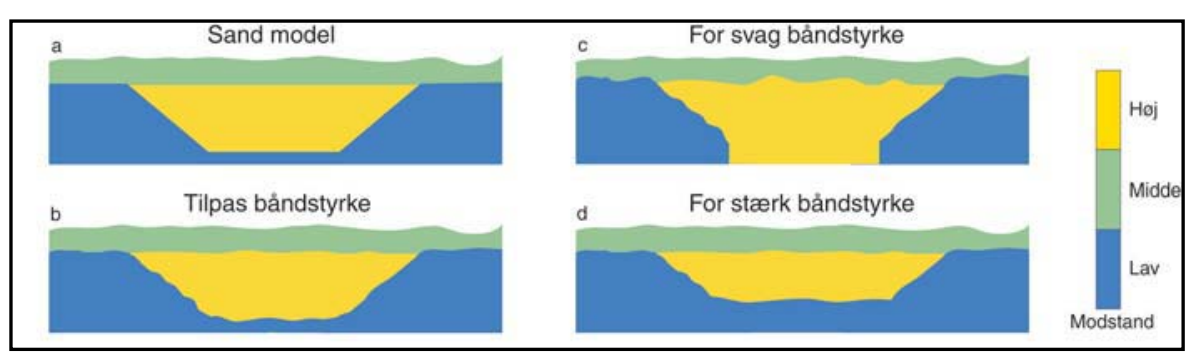

Illustration af en dal opmålt med eksempelvis SkyTEM. a) Den sande model. b) LCI-tolket profil med tilpas båndstyrke - modellen opløses godt. c) LCI-tolket profil med for svage bånd-modellen opløses dårligt, dalbunden findes ikke. d) LCI-tolket profil med for stcerke bånd-modellen opløses dårligt, dalbunden haves. (c) og (d) fører til en fejltolkning af geologien. (Grafik: Lars H. Jacobsen)

for løse, vil informationen, der sendes videre fra en model til en anden, være utilstrækkelig, hvorved båndene i yderste konsekvens ingen effekt vil have og derfor ikke vil forbedre opløseligheden. Dette er illustreret $\mathrm{i}$ figuren øverst til højre.

Da båndene som nævnt skal afspejle variationen i geologi mellem to modeller, er styrken af disse i høj grad afhængig af afstanden mellem to sammenbundne modeller, idet det antages, at variationen mellem to tætliggende modeller er mindre end variationen mellem to modeller, der ligger længere væk fra hinanden. Det betyder, at der hhv. skal bruges stærkere bånd, hvor modellerne ligger tæt, og løsere hvor der er en større adskillelse. Som det kendes fra fx PACES og SkyTEM, varierer afstanden mellem modellerne konstant, hvilket betyder, at det hele tiden er nødvendigt at korrigere båndstyrkerne. Det har i analysearbejdet vist sig, at hvis afstanden mellem to modeller ikke er for stor, så er det fornuftigt at afstandskorrigere båndene proportional med kvadratroden til den forholdsvise afstandsændring.

I figuren nederst til venstre er der illustreret to scenarier, der viser, hvorledes profilorienterede data aktuelt sammenbindes. Illustration (a) viser profilorienteret LCItolkning, hvor modelgrundlaget er baseret på én datatype med rimelig datatæthed ( $\mathrm{fx}$ MEP, PACES eller SkyTEM). Sammenbindingen foregår fortløbende langs profilet med bånd mellem nabomodellerne. Illustration (b) viser profilorienteret LCI-tolkning, hvor modelgrundlaget er baseret på to datatyper (fx MEP og TEM). Her sker sammenbindingen både internt mellem modeller baseret på samme datatype samt mellem modeller baseret på forskellige datatyper.

\section{LCI-tolkning af SkyTEM-data fra Sydthy}

Som eksempel på anvendelsen af LCI-metoden vises her udvalgte resultater, som er opnået på basis af LCI-tolkning af et større SkyTEM-datasæt indsamlet i Sydthy for Viborg Amt. I forbindelse med kortlægningen er der indsamlet ca. $350 \mathrm{~km}$ produktionsdata, som er optaget således, at der skiftevis udlæses datasæt med lavt og højt moment.

Opsætning af de profilorienterede LCItolkninger er foretaget langs de fløjne linier ved at sammenbinde modellerne fortløbende, således at lavmoment-modeller binder til en højmoment-model, som igen binder videre til en model med lavt moment. Der er i dette tilfælde blevet anvendt bånd på modstandsog på lagtykkelsesparametrene, hvis styrker er skalleret med kvadratroden til den forholdsvise afstandsændring.

Data er alle blevet tolket i modelsektioner med 4, 5 og 6 lag (inkl. luftlaget). Resultaterne af disse tolkninger med forskellige antal lag er ud fra residualerne på data og bånd samt ud fra parameterbestemmelsen blevet vurderet i forhold til hinanden. Det har således været muligt vurdere kvaliteten af tolkningerne samt at udvælge de modelsektioner, hvor data og bånd tilpasses af modeller med færrest antal lag, hvorved der i videst muligt omfang ikke tolkes overflødige lag (pseudolag). 


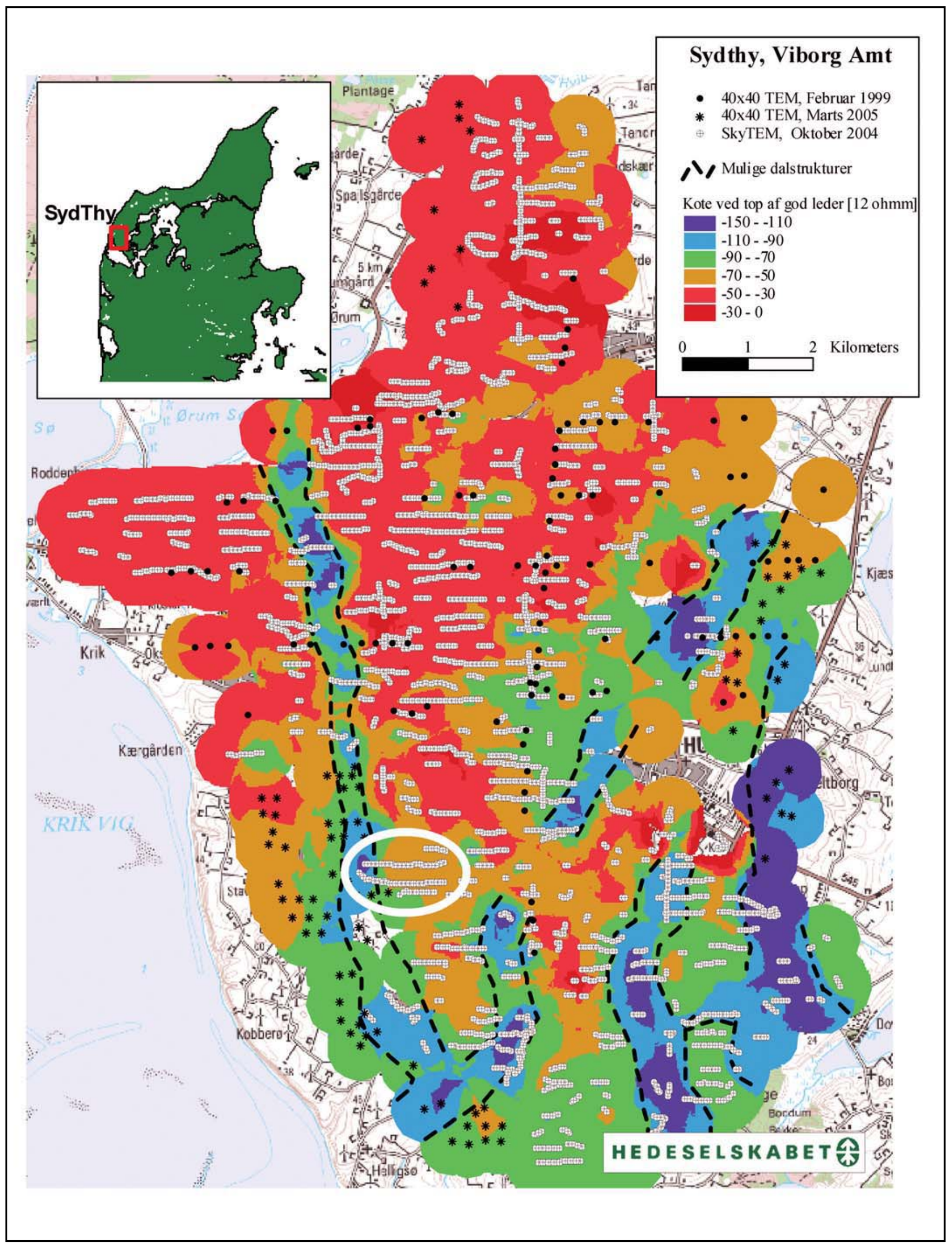

Fladekortet viser koten til den gode leder i Sydthy fundet på baggrund af SkyTEM-data, som er blevet LCI-tolket. Den hvide ovale cirkel markerer udvalgte data, som prcesenteres i figuren øverst på noeste side. (Grafik: Anders Edsen) 
Resultat af profilorienteret LCI-tolkning Som det fremgår af fladekortet over koten til den gode leder i figuren på modstående side, har resultatet af kortlægningen bl.a. været, at der er fundet en række strukturer, der tolkes som begravede dale. Den geologiske tolkning heraf verificeres i skrivende stund, idet Viborg Amt udfører en række boringer på baggrund af resultaterne. Det skal bemærkes, at strukturerne, der går på tværs af tolkningslinierne, opløses, hvilket bl.a. afspejler, at båndstyrken har været tilpas.

I figuren til højre er vist et udvalgt profil, hvor data henholdsvis er tolket med MCI- og LCI-metoden (MCI-metoden har indtil dato været anvendt til at tolke SkyTEM-data. Med MCI-metoden sammentolkes et datasæt med lavt moment og et datasæt med højt moment, hvorved der opnås én midlet model pr. to datasæt). Som det fremgår heraf, bevirker LCI-metoden at modelgrundlaget fordobles i forhold til, hvis data tolkes med MCI-metoden. Det skyldes, at der med LCI-metoden opnås en særskilt model for hvert datasæt, mens der i forbindelse med MCI-metoden anvendes et datasæt med lavt moment og et med højt moment for hver midletmodel.

I figuren kan det samtidig ses, at de to tolkningsmetoder generelt opløser de overordnede strukturer lige godt. Dog fastlægges der med MCI-metoden ikke en god leder i den centrale del af profilet. De horisontale bånd giver imidlertid anledning til, at der trækkes tilpas information med ind fra siderne, således at der i det LCI-tolkede profil opløses en god leder i bunden af modellerne. Denne gode leder udgør tilsyneladende den ene flanke af en dalstruktur. Strukturen bekræftes på fladekortet i figuren på modstående side, hvor det ses, at den kan erkendes både nord og syd for profilet. Båndene giver endvidere anledning til, at der opnås et mere sammenhængende modstandsbillede, hvor modellernes udseende varierer mere jævnt.

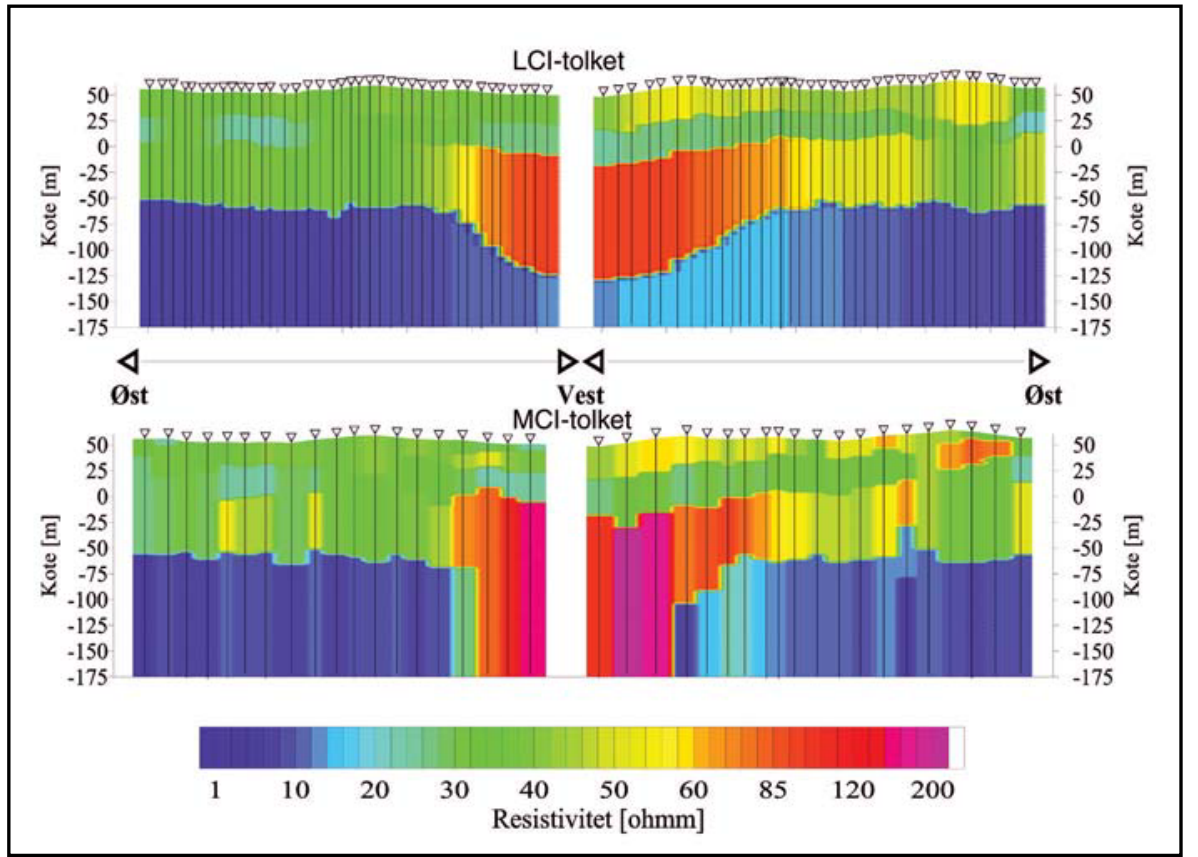

SkyTEM-data fra et udvalgt profil, der i figuren på modstående side er markeret med en hvid cirkel. Data er tolket med øverst LCI-metoden og nederst MCI-metoden. (Grafik: Anders Edsen)

I profilet med de MCI-tolkede modeller kan der i den venstre side ses to modeller, hvori der opløses et lag med forhøjet modstand. I det LCI-tolkede profil opløses dette lag ikke, idet båndene giver anledning til, at modstanden udglattes. Det er imidlertid et udtryk for, at informationen om laget med forhøjet modstand er for svag, idet det ellers ville have slået mere igennem $\mathrm{i}$ både de MCI- og LCI-tolkede modeller. Som det fremgår af figuren nedenfor, er det et billede på et udtalt ækvivalensproblem (der tales om ækvivalens, når det inden for datausikkerheden er muligt at tilpasse data med flere forskellige modeller lige godt.), som det med de horisontale bånd ikke er muligt at opløse. I/3/ ses det imidlertid, at det ved at kombinere a priori-viden fra $\mathrm{fx}$ boringer $\mathrm{og}$ brugen

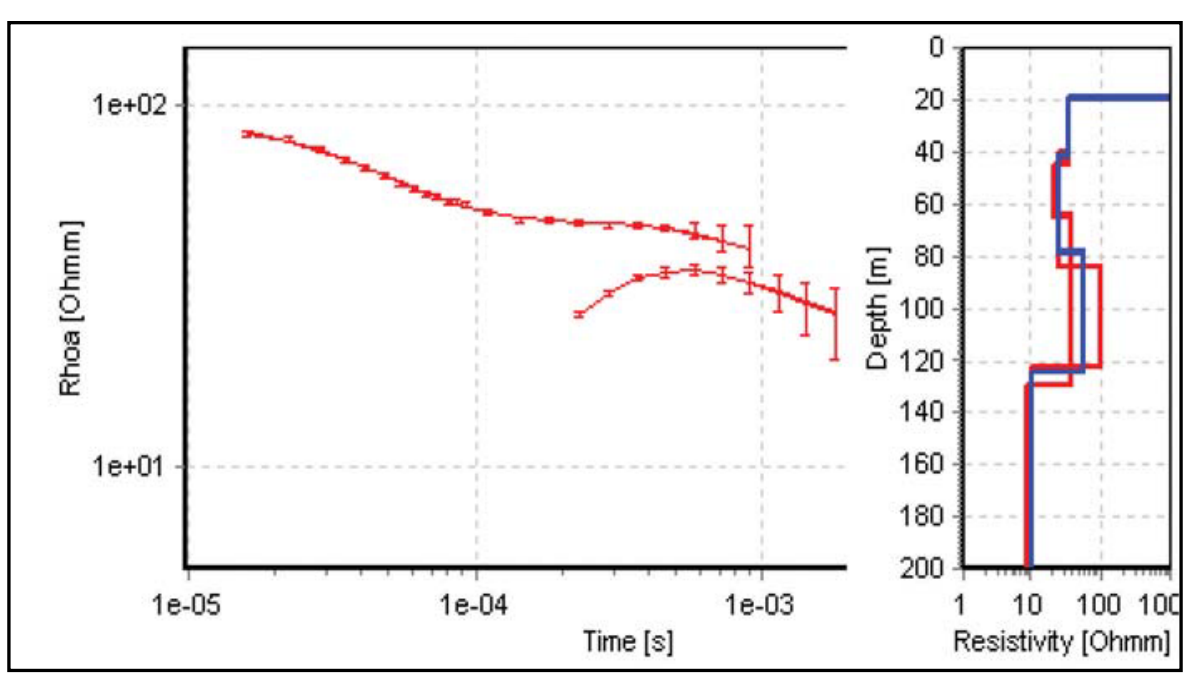

Eksempel på cekvivalente modeller, hvor det inden for datausikkerheden er muligt at tilpasse flere forskellige modeller lige godt. Som det fremgår i dataplottet falder de tre datakurver overordnet oven i hinanden, mens de opløste modeller er forskellige. (Grafik: Lars H. Jacobsen) af horisontale bånd i højere grad er muligt at løse ækvivalens problemer.

\section{Den videre udvikling af LCI-metoden}

På sigt er det naturligt at videreudvikle LCImetoden, således at den kan benyttes til at tolke data, der ikke kun er fordelt langs profiler, men ud over fladen. Dette vil resultere i en pseudo tredimensional tolkning-baseret på én-dimensionelle modeller. Tolkningsalgoritmen har allerede indbygget disse muligheder, men det er endnu ikke fastlagt, hvordan fx båndende imellem de enkelte sonderingspunkter skal indstilles. Da det pga. de meget store datamængder heller ikke er muligt at tolke mange kvadratkilometer data på en gang, skal der udvikles en metode til at stykke et kortlægningsareal op i mindre stykker, som kan tolkes delvist uafhængigt - uden at der går geologisk information tabt.

Det forventes, at dette udviklingsarbejde finder sted i efteråret 2005, og metoden derfor vil kunne anvendes til produktionstolkning $\mathrm{i}$ begyndelsen af 2006 .

\section{Referencer:}

1/ GeoFysikSamarbejdet, december 2002: LCI tolkning af geoelektriske data - verificering af metoden. Findes på $w w w . g f s . a u . d k$

12/ GeoFysikSamarbejdet, marts 2004: Kombineret LCI tolkning af MEP og TEM data - Koncept og tolkningsresultater. Findes på www.gfs.au.dk

\section{/3/ GeoFysikSamarbejdet, september} 2004: Lateral sambunden tolkning af transiente elektromagnetiske data. Findes på www.gfs.au.dk 